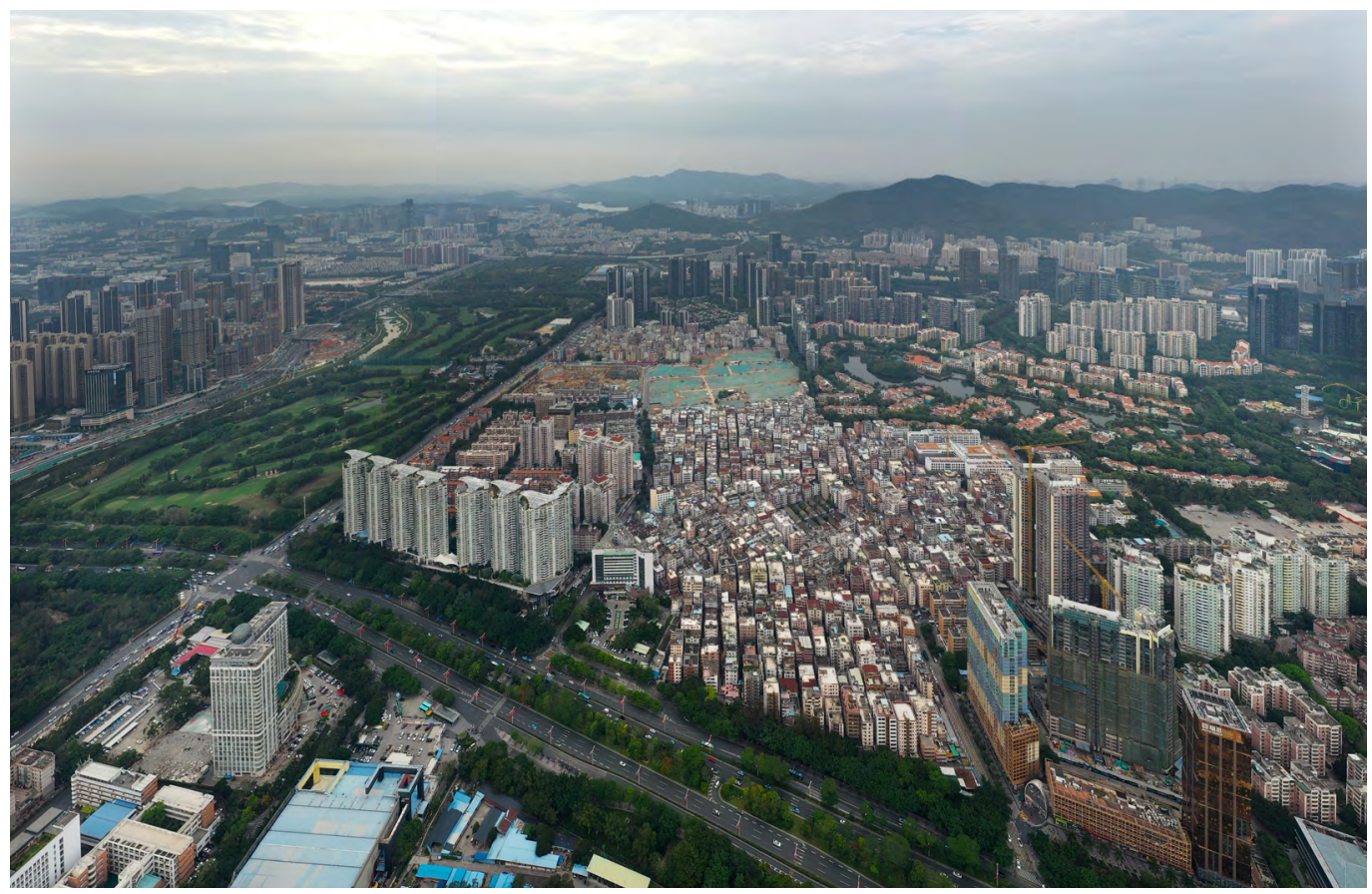

\section{The End of an Era?}

\author{
Two Decades of Shenzhen \\ Urban Villages
}

\section{Mary Ann O'DONNELL}

Discussions of 'urban villages' tend to refer to this term as if it had had a universal and fixed meaning. In this way, the phrase comes to implicitly refer to the present moment, telescoping our understanding of rural and urban relations to the present. By looking back at the experience of Shenzhen over the past decades, this essay restores urban villages to their historicity and unpacks the unacknowledged moral judgments that often underlie our understanding of these places.
Baishizhou aerial view. Camera is pointing north across Shennan Road. PC: Luo Kanglin 罗康林
W e speak of 'urban villages' (城中村) as though the term had a universal and unchanging definition. However, when we visit any such place in Shenzhen, we quickly realise that differences abound. In the inner districts, for example, the dominant village structure is a six to eight-storey rental tenement or 'handshake building'. In contrast, the handshake buildings that define urban village spaces in collective manufacturing areas along national expressway G107-the first highway to connect Shenzhen to Guangzhou via Dongguan-are often 16 to 18 storeys high. The layouts of inner and outer urban villages are also recognisably different. Those in inner districts are smaller and denser than those in outer districts. Patterns of use further distinguish urban villages from one another. At this 
finer level of analysis, we discover, for example, that villages in Bantian provide low-priced housing and shops for Huawei workers, while, in contrast, the fashionable restaurants and coffee shops of Futian urban villages offer tasty experiences for young white-collar workers in the downtown area. If that were not enough, when we look at urban villages from a longer historical perspective, even more differences become salient. The compounds that make the Longgang Hakka villages distinctive, for example, were built during the late Qing period, while local ancestral halls in Shajing and Fuyong trace village history back to the Song Dynasty (960-1279 CE). Indeed, the Longjin Pagoda in Shajing is one of the city's oldest landmarks located above ground-and, yes, we need to specify 'above ground' because below ground there are even older settlements throughout Shenzhen. Roughly 1 kilometre east of Nantou Ancient City, near Honghua Estates on the Nantou peninsula, for example, nine Han Dynasty (202 BCE - 220 CE) graves were discovered, while artefacts discovered at the Xiantouling Neolithic site on the Dapeng Peninsula have been dated to 7,000 years before the present (Peng 2015).

Using the term 'urban village' without specifying a historical era is misleading. Without temporal qualification, the phrase implicitly refers to the present moment, telescoping our understanding of rural and urban relations to the present. The history of urban villages is thus converted into a comparison of two kinds of urban environments: urban villages versus planned communities. In this comparative scheme, the implied research question is straightforwardly developmental: how do we transform villages into communities? In turn, this interrogative idea leads to technical questions such as: are handshake buildings more or less modern than steel and glass towers? Are wide streets more or less convenient than narrow streets? How necessary are landscaped parks to a comfortable lifestyle? Consequently, the lack of historical specification leads to an unacknowledged moral judgement: if planned communities are superior to urban villages, the people who live in planned communities are also superior to the people who live in urban villages. This unacknowledged moral judgement is then simplified into 'commonsense' action: transforming rural places and people into urban places and people through 'rural urbanisation' (农村城市化).

In Shenzhen, rural urbanisation must be understood as successive forms of administrative restructuring, reflecting both the historical legacy of urban-rural inequality under the hukou system and contemporary efforts of differently situated agents to reform and open the planned economy (Wang 2005; Young 2013). In 1979, Guangdong Province first elevated Bao'an County to Shenzhen municipality and only subsequently, in 1980, did the central government approve the designation of Shenzhen as a Special Economic Zone (SEZ). This is an important, but often overlooked, point: urban status preceded special economic status. Also overlooked is the fact that the elevation of Bao'an County to Shenzhen City did not mean Bao'an residents became citizens of Shenzhen City. Instead, Bao'an residents continued to hold rural hukou within their natal villages. In contrast, official migrants received Shenzhen urban hukou via their Shenzhen work unit. Moreover, unofficial migrants to the city carried their hometown or home village status, which in turn determined their ability to obtain a Shenzhen hukou. Crudely speaking, urban hukou could be transferred to Shenzhen, while rural hukou could only be transferred to Shenzhen via another city. In practice, this meant that rural migrants had to first transfer their village hukou to the town or city that oversaw their village and only then could they apply for Shenzhen hukou.

Shenzhen's cultural geography became even more complicated in 1981, when Bao'an County was reinstituted and Shenzhen City was partitioned into the SEZ and Bao'an County, with only sections of the SEZ designated urban and Bao'an County demoted to rural status. The internal border between the SEZ and Bao'an was known as 'the Second Line' (二线)-a reference to the First Line: the Shenzhen-Hong Kong border. A wall was built between the urban and rural sections of the city and non-Shenzhen residents needed travel passes to cross from Bao'an into the SEZ. Although border regulation eased around 2003-04, the presence of this barrier lingers in everyday conversation and today the original SEZ is known 
as the inner districts (关内, literally, 'inside the gate'), while the area that was reinstituted as Bao'an County and now comprises six city districts is known as the outer districts (关外, 'outside the gate'). Rural urbanisation also refers to a two-step policy through which remnant rural land was transferred to the city and people with Bao'an hukou were given Shenzhen hukou. The inner districts completed rural urbanisation in 1996 and the outer districts in 2004, when Shenzhen officially became the first Chinese city without villages.

The unacknowledged moral judgement that urban people and places are superior to rural people and places is also misleading at a second level, because rural urbanisation has not only oriented policy, but also shaped community, family, and individual aspirations beyond official urban borders. During the 1980s and into the 1990s, communes, townships, and villages built periurban spaces within their borders that have been understood as a Chinese variant of the desakota-a hybrid rural-urban space that characterised urbanisation in Indonesia during the 1980s (Guldin 1996). In Shenzhen specifically, rural subjects worked within and against Shenzhen's hukou system to achieve different levels and differently recognised forms of urbanisation. The 'new village' (新村) was the local form that desakota urbanisation took in Shenzhen. After the completion of the rural urbanisation process, however, when the city turned its gaze to the new villages, it found them to be 'dirty, chaotic, and substandard' (脏乱差). New villages, which had been celebrated as examples of the success of Reform and Opening Up, were suddenly downgraded to 'urban villages', which were seen as urban blight. In the rest of this essay, I track the transition from new village to urban village, arguing that the moral judgement that infused the original rural urbanisation policy was repurposed to justify official renovation of the city's villages. Indeed, this prejudice legitimated what was otherwise recognised as a blatant land grab. After all, the villages were located not only in key areas of the city, but also technically outside the official urban plan, which made them vulnerable to large-scale demolition and redevelopment or 'demolition and eviction' (拆迁), as the process is referred to in everyday conversation.

\section{Desakotasation with Shenzhen Characteristics: The Era of New Villages, 1979- 2004}

Before the promulgation of the 1986 Special Zone Master Plan, there were only two designated urban areas in the Shenzhen SEZ, Luohu and Shekou. The Luohu urban area extended from the train station to Shanghai Hotel, while the Shekou urban area was concentrated around Chiwan Port and the Sea World area (see also Zhou's essay in the present issue). These newly formed urban areas were designated for manufacturing, while the remaining rural area was designated for agricultural production. This understanding of specific urban and rural functions had at least two effects on the shape of the city in the 1980s. First, in planned places, commercial agriculture became an important feature of the landscape. In the inner districts, in addition to the Rural Research Institute, Chegongmiao became a poultry farm, while in the outer districts, Guangming Overseas Chinese Farm specialised in producing milk for export to the SEZ and Hong Kong. Second, villages immediately adjacent to these new urban spaces had commercial opportunities that drew from their 'food source' designation. Traditional housing and public spaces quickly became sites for markets and restaurants-important centres for everyday transactions. These village marketing spaces also became sites where people could purchase everyday 'Hong Kong' goods, such as umbrellas, blue jeans, and small electronics, as well as the video and audio tapes that introduced mainland residents to Hong Kong and Taiwanese popular culture. The contribution of extant rural society to the construction of the new city was even more obvious in the outer districts. The new Bao'an County seat was situated just past the Second Line in Fanshen District, which had only been settled 
during the so-called Fishing Reform (c. 1950-57) (A. Du 2020). In contrast, the main urban area was at Xixiang, which had a vibrant market and, during the 1980s and well into the 1990s, was the 'centre' of urban life in Bao'an.

During the 1980s, this commercial activity allowed rural collectives to build 'new villages'. At first, new villages comprised housing, marketing, and industrial spaces. The most common form of housing was a 2.5-storey home for individual families. Markets and restaurants were conveniently located, while collective industrial parks were built on nearby farmland. Of course, as the urban areas of Luohu, Shekou, and Bao'an expanded at Shenzhen speed, neighbouring new villages adapted to the changing environment. By 1992, however, when the city began integrating collectives into its apparatus, new villages were already undergoing site-specific transformations that were related to their location. Luohu, Shangbu, and nearby Futian villages, for example, were already providing housing for unofficial immigrants, while along G107, collectives were building the large industrial parks that would provide the backbone of Shenzhen's manufacturing boom during the 1990s. These economic functions further intensified commercial urbanisation in the villages. Handshake buildings quickly became the most common building type, as villagers took advantage of the lack of housing for migrants in the city proper. The first floor of handshake buildings was dedicated to commercial functions, while the second to sixth floors were dedicated to housing. There was further differentiation in the inner and outer districts. In the inner districts, villages offered urban amenities for migrants who worked in formal areas of the city. For example, many of the migrants who transformed Shangbu Industrial Park into Huaqiangbei Electronics Street lived in Gangxia Village, while the workers who made Chegongmiao an important manufacturing centre lived in Shangsha and Xiasha villages (after the chickens had left, of course!).

During the 1990s, as Shenzhen transitioned from being a special zone with two urban centres into a metropolis with dispersed urban functions, new villages provided spatial solutions to the interrelated problems that arose from both planned urbanisation and unplanned immigration to the city. On the one hand, new villages afforded marketing opportunities to all migrants. When we look at early housing estates, for example, we discover that they were built only for housing. Many workers who lived in official housing could eat in work-unit canteens. However, families who wished to cook at home generally had to shop at a new-village market. In addition, when we look at questions of economic opportunity in the city, we also discover that new villages afforded opportunities that were unavailable in the formal city. At the individual level, these villages offered manufacturing employment to rural migrants as well as investment opportunities for migrants who had some capital. For example, many handshake buildings and shops were built and opened by first-generation migrants. At the collective level, new villages were the spatial form through which the local area urbanised in the absence of formal investment. In fact, during the first decades of the SEZ, most immigrants lived either in or near a village, relying on it to meet their everyday needs. Moreover, by 2000, more than half of the city's population lived in a new village, not including those who had already transitioned from residing in one of these villages to living in 'mainstream' housing.

\section{Restructuring Peri-Urban Shenzhen: Tianmian to Gangxia, 2004-2009}

Tianmian was the first village along the Shennan Road, the city's main thoroughfare, to be renovated. The construction of Shennan Road-a modern, landscaped boulevard-was also central to the young city's self-presentation both at home and abroad and, in 2004, it was named one of the city's 'eight sights'. The village's location at the border between the 'old' city centre in Luohu and the proposed city centre in Futian meant Tianmian was an important symbol of the transition from 'new' to 'urban' villages in Shenzhen (O’Donnell 2018). In the early 1980s, when the 
Futian Commune restructured as a subdistrict under Shangbu Management Area, one of the teams of the commune, Gangxia, separated into Tianmian and Gangxia villages. Tianmian was on the northern side of Shennan Road, while Gangxia was further west on the southern side of the road. When the 1986 urban masterplan was promulgated, it extended planned urbanisation in the city through five clusters, which were separated by greenbelts. When the border between LuohuShangbu and Futian was designated, Tianmian was located within the greenbelt, while Gangxia was to its west. In the 1980s and 1990s, both Tianmian and Gangxia took advantage of their location to build factories. Finished products-electronics and toys, for example-were loaded on to pallets and into containers and initially shipped abroad via the Wenjingdu checkpoint and subsequently via the Huanggang checkpoint. Individual villagers accumulated the capital necessary to build private homes by working in factories, operating small shops, and smuggling goods from Hong Kong to sell in Shenzhen markets. They also acquired investment capital from Hong Kong relatives and investors. In 1996, the same year rural urbanisation was completed in the inner districts, the city promulgated its second masterplan, with its focus on building a new city centre in Futian. The centrepiece of this development was a corridor comprising the main government building, the Civic Centre (市民中心), a library, symphony hall, as well as a park and elegant high-rises, extending south from the Deng Xiaoping sculpture atop Lianhua Mountain to the Shenzhen Convention and Exhibition Centre near the Hong Kong border. As part of this process, in 1998, the greenbelt that separated Luohu-Shangbu from Futian was upgraded to become 'Central Park' (中心公 园). Suddenly, Tianmian was next to the city's most iconic park, while Gangxia was across the street from the city's proposed new government complex. Consequently, the 2004 renovation of Tianmian indicated that the city intended to complete the formal urbanisation process, remaking extant new villages as legitimate communities.

Five years later, in 2009, Shenzhen began renovating Gangxia Village. The differences between the levels of investment in the renovation of Tian- mian and Gangxia suggest that, between 2004 and 2009, the city's imagining of how the rural would fit into Shenzhen's future had changed. Unlike in Tianmian, which included at least three classes of housing and locations for mum-and-pop commercial activities, redevelopment in Gangxia entailed massive compensation packages and replacement of the dense, multi-use urban village environment with an upscale, gated community, office buildings, and a mall. Indeed, the renovation of Gangxia reputedly created 20 billionaires in a drawn-out negotiation that was staged directly south of the Civic Centre, solidifying class antagonisms that had been present but not dominant in Tianmian-style renovations (Shi and Peng 2009). In the Tianmian renovation, the urban village comprised four general areas: high-end commercial, high-end residential, mid-range commercial and residential, and low-end commercial and residential. This layout has allowed for a diverse spectrum of residents and livelihoods within the village, suggesting an inclusive understanding of rural urbanisation. In contrast, the redevelopment of Gangxia entailed only the construction of high-end commercial and residential buildings. When Gangxia Village was demolished, an estimated 100,000 people were evicted. Only villagers who had equity in the old village received compensation and could afford to move back to the area, while the majority of Gangxia residents relocated to other urban villages that were not as conveniently located.

What changed between 2004 and 2009? The simple answer is the city's view of itself and the place of urban villages therein. In 2004, the relationship between new villages and the city shifted when the last of the rural areas in the outer districts was formally incorporated into the city apparatus, making Shenzhen China's 'first city without villages'. This unification was not only administrative, but also infrastructural. From 2004, the city provided new villages with water and electricity as well as increased urban management. The incorporation of villages into the urban apparatus initiated a new discussion about these spaces. When villages were separated from the city by function, the discussion focused on what kind of 'rural' space 'new villages' were. In this discussion of rural urbanisation, the conversation 
emphasised the 'newness' of this form of rural space, and new villages were held up as successful examples. In contrast, once villages were incorporated into the city proper, the conversation emphasised 'urban' standards. In this discussion, urban villages appeared as failed or incomplete urbanisation, initiating efforts to renew 'dirty, chaotic, and substandard' urban spaces into planned communities.

In 2009, Shenzhen promulgated the Shenzhen Urban Renewal Method (深圳市城市更新 办法), encouraging developers to draw up renovation plans that would bring urban villages into alignment with the city's view of itself as a world city. That year, 93 village renewal projects were approved citywide, tripling investment in redevelopment, from 672.3 million RMB in 2009 to 2.51 billion RMB in 2010 (Liu and Lin 2015). This large-scale project to transform the city had interrelated material and social effects. On the one hand, the city was increasingly integrated. Redevelopment of Shenzhen's urban villages began along Shennan Road and in the older sections of the city. In addition to Gangxia, the most famous of the Shennan Road renewals from the 2010s included Caiwuwei and Dachong, while throughout the inner districts, urban renewal began with urban villages near Luohu and Shekou, the 'old' city centres. On the other hand, as displaced residents left demolished villages, unplanned urbanisation in remaining urban villages intensified. Increasing population density in these remaining villages led to both a higher cost of living and more capital investment in the built environment. Coffee shops and breweries that targeted young white-collar workers exemplified this new form of investment and expenditure.

\section{The End of an Era? Baishizhou, 2010-2019}

Throughout the 2010s, Baishizhou prospered as an unrenovated urban village (see, for instance, Chen 2017: 223-63; Du Juan 2020: Ch. 8; O’Donnell and Bolchover 2014). Located on Shennan Road, Baishizhou absorbed the excess population displaced from Gangxia and Dachong in addition to other inner district urban villages. Three classes of displacement characterised movement into Baishizhou. First, start-up companies that no longer had access to cheap and convenient spaces moved into the village's factories. These companies included graphic design, clothing design, and IT prototypes. Second, families who wanted their children to continue their schooling in the inner districts also moved into the village. Third, restaurant entrepreneurs opened sites in Baishizhou. The most popular restaurants were located on 'Beer Street'-a converted commercial area in the middle of the village. In turn, these displacements made Baishizhou one of the most economically diverse neighbourhoods in the inner districts, attracting working-class families, young architects, and innovative entrepreneurs. Moreover, the village's convenient location meant it remained an important destination for new migrants to the city, who temporarily stayed in its many motels and hostels while looking for work or more permanent housing.

In 2013, Handshake 302 Art Space-an independent art collective that creates site-specific public art-rented a 12-square-metre efficiency apartment in Baishizhou. Like other renters, we chose this 'base' because it was cheap and convenient. Indeed, there was no other place along Shennan Road where it was possible to jumpstart a non-traditional art practice as cheaply as in Baishizhou. One of our earliest projects was 'Discover Baishizhou' (发现白石洲), which treated the urban village as a 'tourist destination' or a 'museum'. During the tour, we introduced visitors to seven micro-environments in the village, emphasising how our bodies interact with the city. The tour started at Baishizhou metro exit A, where the neighbourhood is connected to mainstream Shenzhen by metro train or bus. As a transportation hub, Baishizhou connected the urban village to the rest of Guangdong and southern China. Indeed, many visitors from the Huizhou, Meizhou, and Chaoshan areas jokingly said: 'When my hometown bus comes to Shenzhen, the first stop is Baishizhou!' The tour then entered the village through a small alley, walking past a coffee shop, bikes, and buildings to a Y-shaped intersec- 


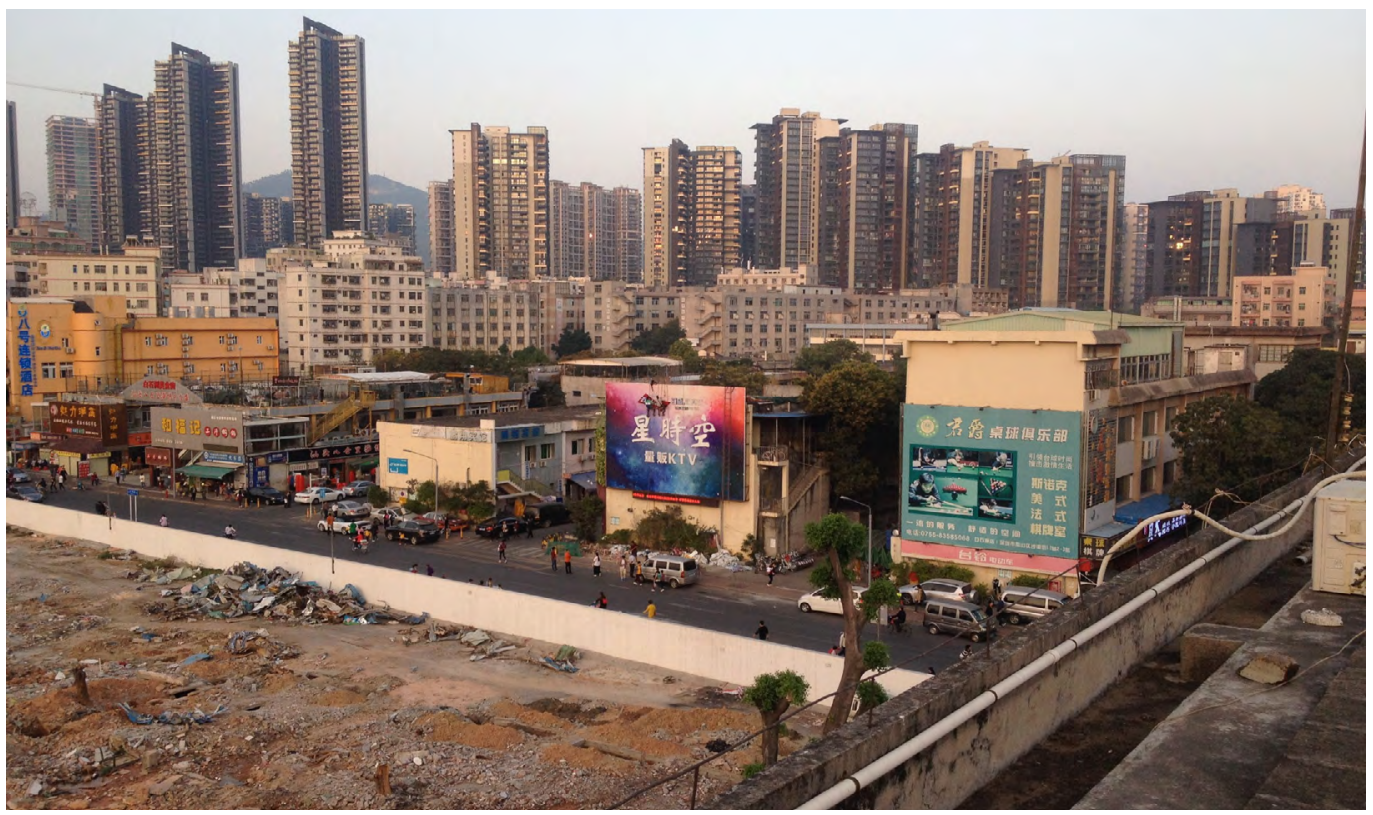

Roof top view of Baishizhou, demolished western section of the Shahe Industrial Park in the foreground, still occupied eastern section of the Shahe Industrial Park in the middle ground, and OCT residential towers in the background. PC: Mary Ann O'Donnell.

tion. Motorbikes and small trucks zipped past us as we entered a small plaza where during the day children played while venders set up mobile kiosks that at night became busy restaurants. At the southern edge of the plaza was a well, where migrant women could wash clothing, and a narrow alley that served as a marketing street. Behind the plaza were 10 row houses, built in 1958-59 when several dozen families were relocated from a village flooded by the creation of the Tiegang Reservoir in Longhua. We then followed an alley to the wall that separated Baishizhou from Shenzhen's most expensive housing development, 'Portofino', and then turned into another alley, which led us to the Bo Gong shrine. Next, we visited a vibrant public area near the Jiangnan Department Store. In front of the supermarket was an exercise area, while to its north was a public plaza and stage. We then entered the eastern section of the Shahe Industrial Park, where we ended the tour at a local brewery, chatting, drinking home-brewed beer, and eating cheap but delicious barbecue. Participants in the Discover Baishizhou project who had never been to Baishizhou were impressed by the diversity and prosperity of the urban village's micro-environments, while those who had lived in Baishizhou during the 1990s and 2000s were able to rekindle childhood memories among the kiosks and alleyways.

Handshake 302 was in residence in Baishizhou from the autumn of 2013 to the summer of 2019, during which we created original artwork that grew out of our exploration. These reflections on the meaning and importance of 'urban villages' to Shenzhen intensified in 2016, when the destruction of Baishizhou began with the demolition of the western section of the Shahe Industrial Park. At the end of 2017, entrepreneurs in the eastern section of Shahe Industrial Park were evicted, although the buildings were not demolished. To 


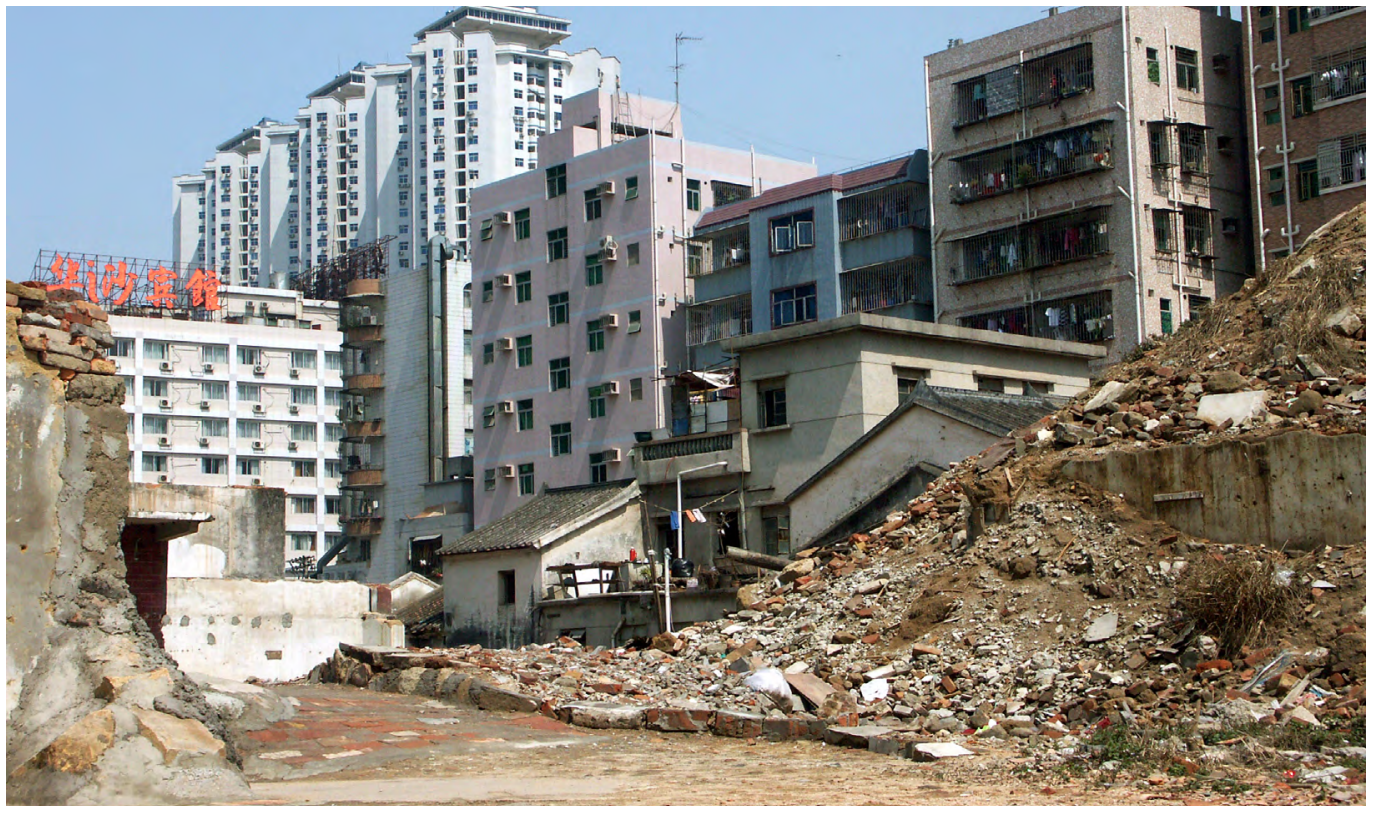

Xinzhou Village, Futian. Early 'village renewal' projects focused on removing old village settlements. In the picture foreground are 'farmer housing' that were built during the Mao era, while the 2.5-storey concrete house was one of the first 'new farmer houses' that were built during the 1980s. In the middle ground are 1990s-era handshake buildings and a village-operated hotel, while in the background is a Futian housing development, c. 2000. PC: Mary Ann O'Donnell.

ensure people moved out, water and electricity were cut off in January 2018. About 18 months later, in the summer of 2019, entrepreneurs and residents were evicted from neighbouring handshake buildings and, by early 2020, most businesses had closed. Until the mass evictions of 2019, Baishizhou was one of the most vibrant spaces in the inner districts, representing for many Shenzheners the ideal 'urban village'.

\section{From Urban Villages to Low-Income Suburbs?}

A brief comparison of inner and outer district villages makes salient how special inner district villages were-first, as 'new villages' (1979-2004) and then as 'urban villages' (2004 - c. 2019). During the 1990s era of new villages, for example, resi- dents of villages in and around Luohu and Shekou could not only walk or ride bikes to their jobs, but also take advantage of city-level cultural resources, such as libraries, theatres, and museums. Inner district new villages became de facto destinations because they provided services and goods that were not yet available in the SEZ. Once these amenities were available, urban villages offered cheaper access to services and goods in the formal city. Moreover, as the 2000s transitioned into the 2010s, inner district urban villages increasingly became sites for entrepreneurial creativity and fashionable consumption. After the completion of administrative rural urbanisation in 2004, planned cultural investment in the inner districts made inner district villages even more attractive as destinations. The construction of the Civic Centre exemplified this trend as residents in Tianmian, Gangxia, and other Futian urban villages could now easily visit the city's main museum, library, and performance hall. 
At the same time, Nanshan emerged as home to Shenzhen University, the national-level museums of Overseas Chinese Town, and the Hi-Tech Park, further enhancing cultural opportunities in the inner districts. Consequently, during the 2010s, Baishizhou was not the only urban village to emerge as a consumer destination for young people. Villages in Luohu and Futian districts also became 'playgrounds', offering tasty meals, tea and coffee shops, and vibrant streets for window-shopping, while Shenzhen University's 'backyard', Guimiao, saw the rise of various creative industries. Thus, during the 2010s, residents of Baishizhou lived within walking distance of or a short trip on public transport from some of the city's best creative jobs and cultural resources.

In contrast to the social and cultural opportunities symbolised by inner district villages, outer district villages have represented different forms of exclusion. On the one hand, before 2003-04, enforcement of the Second Line meant that, if migrants arrived in Bao'an without first securing a travel pass, they could not work in the SEZ, let alone visit its urban areas, cultural institutions, and famous tourist spots. On the other hand, in the outer districts, except for investment in a library, theatre, and park near the new county seat, there was limited investment in cultural resources. Even on national highway G107, the trip from a Shajing Village industrial park to the county seat took at least two hours, while a trip from the eastern reaches of the outer districts could take more than five hours. This geography meant that, in practice, outer district village residents could only access cultural resources through the village that owned and managed the industrial park where they worked. Wanfeng Village, for example, established a Cantonese Opera Troupe, but most villages simply provided outdoor film screenings and ad hoc ping pong tables. Moreover, although outer district cultural policies since 2004 have focused on building schools, libraries, and museums, these resources offer neither the variety nor the quality of inner district institutions. The history of the Pingshan Art Museum illustrates the conundrum of locating cultural resources in the outer districts. Construction of the museum began in 2010 and, in 2011, it began offering summer art programs.
Since then, a cutting-edge art program has been introduced, making the museum one of the city's more interesting cultural resources. However, it is not easily accessible. On the high-speed train, for example, the trip from Futian to the museum takes 45 minutes, while from anywhere else, a one-way trip on public transport to Pingshan Art Museum can take 2.5 to three hours. Local residents do not fare any better since, as part of its upgrading, Pingshan is building commuter estates in thinly populated areas of the city, which in practice means the audience for these new resources is limited to the city's car-owners.

When viewed from the perspective of the development of urban villages within Shenzhen, it seems the 2019 evictions from Baishizhou were a watershed moment. Small enclave villages remain in Luohu, Futian, and Nanshan, but these are neither as large nor as diverse as Baishizhou was. Moreover, they no longer represent affordable housing. Instead, these inner district urban villages thrive to the extent that they can become consumer destinations. Within walking distance of the Civic Centre and nearby office complexes, Futian villages like Shuiwei and Xiasha, for example, have become well-known foodie hangouts. Similarly, villages in Luohu and Nanshan have thrived as consumer destinations for creative, tech, and managerial workers. In contrast, there are limited high-end jobs available in the outer districts. Instead, outer district urban villages still primarily provide affordable housing options to workers in the service and manufacturing industries. The city and its districts have continued to invest in upgrading these villages, increasing urban amenities, including reliable water and electrical connections as well as sanitation services. These improvements have made living in these villages more comfortable. Moreover, investment in nearby schools and clinics has meant that working families are better able to access city services. Nevertheless, this level of investment is oriented to serving the residential population of a village rather than attracting entrepreneurial investment. In this geography of relative segregation, outer district urban villages end up functioning much like a housing developmentresidents return home to sleep, while working and consuming elsewhere. Consequently, outer district 
villages have not evolved into consumer destinations in the same way as inner district villages, but have instead remained relatively isolated, low-cost neighbourhoods, suggesting their future may be as low-income suburbs rather than vibrant urban villages.

\section{Legacies of Rural Urbanisation}

The moral judgement that urban places and people are superior to rural places and people was built into Shenzhen's cultural geography. During the first decade of the SEZ, the construction of the Second Line and the designation of urban versus rural areas within the city proper transposed the inequalities of the hukou system on to Bao'an County. In turn, this led to the unequal distribution of institutional resources, as schools, hospitals, and cultural centres were built, first, in designated urban areas and, subsequently, throughout the SEZ. I have argued that this unequal access to institutional resources was one concrete expression of valuing urban places and people more than rural places and people. By virtue of their physical location, urban residents were able to care for their bodies (in hospitals), their children (in schools), and take advantage of adult learning opportunities (in libraries and museums). This care gap has widened over time, defining class differences between the children born to people with Shenzhen hukou, local Bao'an residents, and unofficial migrants to the city.

Importantly, even as planned urbanisation proceeded, so, too, did unofficial rural urbanisation (desakotasation) and the emergence of new villages as sites of urban possibility. In practice, the location of new villages within the SEZ meant their residents (unofficial or otherwise) had access to the city's institutions with important exceptions, such as educational opportunities and subsidised medical care. That said, commercial treatment in Shenzhen's hospitals and private schools quickly emerged as market alternatives to hukou subsidies. These residents also had access to betterpaying jobs in the city's emergent creative, tech, and managerial sectors. In contrast, in the outer districts, access to high-end jobs and social services has remained a feature of official urban centres, which have been built along metro lines. Moreover, many of the residents of these outer district urban centres work in the inner districts. Consequently, while inner district urban villages afforded opportunities for taking advantage of the city's institutions and cultural resources, outer district urban villages remained relatively isolated from them.

The 15 years from 2004 to 2019 were in many ways a golden era for Shenzhen's urban villages. During the era of new villages (1979-2004), villages were not treated as part of the city proper, which meant the city did not provide residents with public water, electricity, and sanitation services. After the completion of rural urbanisation in 2004, the city not only provided urban villages with these resources, but also began actively integrating them into medical and educational networks. In many ways, access to public services jumpstarted what, in retrospect, could be called the era of urban villages (2004-19). Moreover, as the city's economy diversified, young creatives and managers discovered new forms of consumption in the urban villages, while working-class families were able to take advantage of low-cost housing to provide educational opportunities for their children. In other words, these urban villages afforded pathways to urban belonging (Bach 2010). The 2019 evictions from Baishizhou not only marked the end of this kind of urban village in the inner districts, but also challenged the implicit promise of overcoming rural-urban inequality via the SEZ. Instead, what remain are consumption-oriented villages in the inner districts and affordable housing options in the larger, less central urban villages of the outer districts. What comes next is still unclear, especially in the aftermath of COVID-19 lockdowns and increasingly regulated mobility between Shenzhen and the rest of the country as well as within the city itself. Nevertheless, it seems we need to move beyond a simplistic discussion of 'urban villages' and turn our gaze to the problems brought about by planned urbanisation. What happens in the absence of liminal spaces, where unexpected solutions to urban inequality might emerge? 
This text is taken from Made in China Journal: Volume 6, Issue 2, 2021, edited by Ivan Franceschini and Nicholas Loubere, published 2021 by ANU Press, The Australian National University, Canberra, Australia.

doi.org/10.22459/MIC.06.02.2021.07 